\title{
BMJ Global Health The roles of community health workers who provide maternal and newborn health services: case studies from Africa and Asia
}

\author{
Abimbola Olaniran, Barbara Madaj, Sarah Bar-Zev, Nynke van den Broek
}

\begin{abstract}
To cite: Olaniran A, Madaj B, Bar-Zev S, et al. The roles of community health workers who provide maternal and newborn health services: case studies from Africa and Asia. BMJ Global Health 2019;4:e001388. doi:10.1136/ bmjgh-2019-001388
\end{abstract}

Handling editor Stephanie M Topp

Received 2 January 2019 Revised 25 April 2019 Accepted 25 May 2019
Check for updates

\section{(C) Author(s) (or their} employer(s)) 2019. Re-use permitted under CC BY-NC. No commercial re-use. See rights and permissions. Published by BMJ

Centre for Maternal and Newborn Health, Liverpool School of Tropical Medicine, Liverpool, Merseyside, UK

\section{Correspondence to} Dr Abimbola Olaniran; Abimbola.0laniran@outlook. com

\section{ABSTRACT}

Introduction A variety of community health workers (CHWs) provide maternal and newborn health (MNH) services in low-income and middle-income settings. However, there is a need for a better understanding of the diversity in type of CHW in each setting and responsibility, role, training duration and type of remuneration.

Methods We identified CHWs providing MNH services in Bangladesh, India, Kenya, Malawi and Nigeria by reviewing 23 policy documents and conducting 36 focus group discussions and 131 key informant interviews. We analysed the data using thematic analysis.

Results Irrespective of training duration (8 days to 3 years), all CHWs identify pregnant women, provide health education and screen for health conditions that require a referral to a higher level of care. Therapeutic care, antenatal care and skilled birth attendance, and provision of long-acting reversible contraceptives are within the exclusive remit of CHWs with training greater than 3 months. In contrast, community mobilisation and patient tracking are often done by CHWs with training shorter than 3 months. Challenges CHWs face include pressure to provide MNH services beyond their scope of practice during emergencies, and a tendency in some settings to focus CHWs on facility-based roles at the expense of their traditional community-based roles.

Conclusion CHWs are well positioned geographically and socially to deliver some aspects of MNH care. However, there is a need to review and revise their scope of practice to reflect the varied duration of training and in-country legislation.

\section{BACKGROUND}

Lessons learnt from the Millennium Development Goals era show that a continued shortage of health professionals globally remains a threat to achieving the health-related Sustainable Development Goals and Universal Health Coverage, especially goals relating to maternal and newborn health $(\mathrm{MNH}) .^{1-5}$ There are recommendations to revise current health policies to reflect a sustainable and responsive skills mix of available health professionals and refocus

\section{Key questions}

What is already known?

- There is a wide variety of community health workers (CHWs) in low-income and middle-income settings; most are expected to provide one or more aspects of maternal and newborn health (MNH) care.

What are the new findings?

- The roles of CHWs in MNH care vary with duration of training and whether they are community or facility based.

- CHWs are often expected to provide services that are beyond their scope of practice during emergencies where health professionals are unavailable and/or referral may not be possible.

- Some CHW have limited roles in MNH care despite their training because health professionals may prevent $\mathrm{CHWs}$ from providing those services which are viewed as the remit of health professionals.

\section{What do the new findings imply?}

- There is a need for policy-makers and programme planners to be clearer about the roles and responsibilities of the different types of CHWs and revise their scope of practice to reflect training duration while addressing challenges that prevent $\mathrm{CHWs}$ from providing MNH services stated in their scope of practice.

on community health workers (CHWs) as an important cadre within multidisciplinary primary healthcare teams. ${ }^{6} \mathrm{CHWs}$ are increasingly expected to take on additional tasks including in the area of $\mathrm{MNH}^{7}$

While there is relative clarity in the education and training duration of the different cadres of health professionals, CHWs are often described in generic and non-specific terms. ${ }^{2} 8$ Health professionals have been described as individuals with a first degree or higher qualification following 3-6 years of health-related study in a higher educational institution. ${ }^{9}{ }^{10}$ In contrast, CHWs are 
paraprofessionals or lay health workers with an in-depth understanding of a community's culture and language. Additionally, the majority of CHWs have shorter training than health professionals and their primary role is considered to be the provision of culturally appropriate health services to the community. ${ }^{11}$

This study aimed to explore the scope of practice of different cadres of CHWs with regard to provision of $\mathrm{MNH}$ care in different settings. It is anticipated that findings from this study would guide local and global stakeholders recommending generic but expanded $\mathrm{MNH}$ roles for CHWs, ${ }^{12} 13$ without acknowledging the diversities in their training duration.

\section{METHOD}

\section{Study design, setting and population}

We conducted a qualitative study using a multiple-case study design to explore the training duration, characteristics and scope of practice of CHWs providing $\mathrm{MNH}$ services in sub-Saharan Africa and South Asia. Five study countries were selected using multistage sampling. ${ }^{14}{ }^{15}$ The countries in each subcontinent constituted the firststage sampling units. Subsequently, relevant WHO documents ${ }^{1617}$ were reviewed to identify countries known to have health workforce shortages, high maternal mortality ratios and high neonatal mortality rates. ${ }^{16} 18$ These countries made up the second-stage sampling units and included 42 countries in sub-Saharan Africa and five in South Asia. The third stage entailed a comparison of these 47 countries with the 11 countries where the Centre for Maternal and Newborn Health at the Liverpool School of Tropical Medicine (authors' institution) was implementing the 'Making it Happen' programme to reduce maternal and newborn mortality and morbidity. All 11 programme countries were experiencing challenges with health workforce crisis and maternal and neonatal mortality and were included in the third stage sampling unit. Using a limited literature review, countries with a high density of CHWs providing $\mathrm{MNH}$ services were identified including Bangladesh and India (South Asia) and Kenya, Malawi and Nigeria (sub-Saharan Africa). Within each of these study countries, the location of the Making it Happen programme offices informed the selection of the study districts, states or counties as these offices provided logistic support for the study. A document review was done using the most recent versions of government policy documents which described CHW characteristics and their scope of practice in MNH care. The main cadres of CHWs providing MNH services in these countries include community healthcare providers (CHCPs), community skilled birth attendants (CSBAs), family welfare assistants (FWAs) and health assistants (HAs) in Bangladesh; accredited social health activists (ASHAs) and auxiliary nurse midwives (ANMs) in India; community health volunteers (CHVs) in Kenya; health surveillance assistants (HSAs) in Malawi; and community health extension workers (CHEWs) and junior community health extension workers (JCHEWs) in Nigeria.

To understand and check if these were the main CHW cadres in each country, we purposively selected a sample of community and formal health system level stakeholders as study participants and invited them to participate in the study through email, phone calls and, where possible, face-to-face interview. Written consent was obtained from all study participants in English or in the relevant local language.

\section{Data collection}

Data were collected across the study countries between August 2015 and March 2016. In each study country, we interviewed programme staff at the national and subnational levels and health professionals providing $\mathrm{MNH}$ care in primary healthcare facilities. Lastly, we conducted focus group discussions (FGDs) with CHWs, community health committee members and service recipients linked to the primary healthcare facilities. The principal researcher $(\mathrm{AO})$ conducted key informant interviews (KIIs) and FGDs in English language while local research assistants conducted KIIs and FGDs in the relevant local language of each study setting. A total of 131 KIIs and 36 FGDs were conducted. The most recent versions of 23 country policy documents were reviewed to explore and document $\mathrm{CHW}$ characteristics and scope of practice with regard to $\mathrm{MNH}$. Table 1 shows the study countries, study locations, cadres of CHWs, policy documents reviewed and KIIs and FGDs conducted in each of the study countries.

\section{Data analysis}

To objectively compare $10 \mathrm{CHW}$ cadres with diverse training durations, we grouped CHWs based on findings of a systematic review which categorised CHWs into lay health workers, and Levels 1 and 2 paraprofessional CHWs. ${ }^{11}$ The systematic review described lay health workers as "individuals with little or no formal education who have undergone a few days to a few weeks of informal training" and Level 1 paraprofessionals as "individuals with some form of secondary education and subsequent informal training lasting a few days to a few weeks". ${ }^{11}$ Level 2 paraprofessionals were described as "individuals with some form of secondary education and subsequent formal training lasting a few months to more than a year". ${ }^{11}$ Additionally, we reviewed CHW MNH-related scope of practice against WHO's international classification of health interventions which groups interventions under diagnostic, therapeutic, managing, preventing and others. ${ }^{19}$ Subsequently, we explored the role of each CHW category in providing the different components of MNH care package noting the relationship between CHW category and their scope of practice in MNH care.

Using thematic analysis, we identified, analysed and reported patterns (themes) within the study data in relation to the research objectives. ${ }^{20}$ Quotes and excerpts of quotes (in italics and within quotation marks) are 


\begin{tabular}{|c|c|c|c|}
\hline Country and district/state/county & CHW cadre(s) & $\begin{array}{l}\text { Primary data collection method } \\
\text { and sources }\end{array}$ & $\begin{array}{l}\text { Secondary data (policy } \\
\text { document) references }\end{array}$ \\
\hline Bangladesh: Dhaka and Sirajganj & $\begin{array}{l}\text { Community healthcare } \\
\text { providers } \\
\text { Community skilled birth } \\
\text { attendants } \\
\text { Family welfare assistants } \\
\text { Health assistants }\end{array}$ & $\begin{array}{l}7 \text { KIls with } 7 \text { programme staff } \\
4 \text { KIls with } 4 \text { health professionals } \\
3 \text { FGDs with } 16 \text { community health } \\
\text { committee members } \\
8 \text { KIls with } 8 \mathrm{CHWs} \\
2 \text { FGDs with } 11 \text { service recipients }\end{array}$ & $24,25,38$ \\
\hline India: Delhi, Maharashtra & $\begin{array}{l}\text { Accredited social health } \\
\text { activists } \\
\text { Auxiliary nurse midwives }\end{array}$ & $\begin{array}{l}12 \text { KIls with } 12 \text { programme staff } \\
6 \text { KIls with } 6 \text { health professionals } \\
2 \text { Klls and } 2 \text { FGDs with } 20 \\
\text { community health committee } \\
\text { members } \\
16 \text { KIls and } 4 \text { FGDs with } 51 \mathrm{CHWs} \\
3 \text { KIls and } 1 \text { FGD with } 13 \text { service } \\
\text { recipients }\end{array}$ & $26,27,33,37,41,42,44,47$ \\
\hline Kenya: Nairobi and Kiambu & $\begin{array}{l}\text { Community health } \\
\text { volunteers }\end{array}$ & $\begin{array}{l}7 \mathrm{KIls} \text { with programme staff } \\
13 \mathrm{KIIs} \text { with health professionals } \\
1 \mathrm{KII} \text { and } 4 \mathrm{FGDs} \text { with } 26 \\
\text { community health committee } \\
\text { members } \\
1 \mathrm{KII} \text { and } 7 \mathrm{FGDs} \text { with } 54 \mathrm{CHWs} \\
4 \mathrm{KIls} \text { with } 4 \text { service recipients }\end{array}$ & 28,36 \\
\hline Malawi: Lilongwe & $\begin{array}{l}\text { Health surveillance } \\
\text { assistants }\end{array}$ & $\begin{array}{l}5 \text { KIls with } 5 \text { programme staff } \\
7 \text { Klls with } 7 \text { health professionals } \\
5 \text { FGDs with } 51 \text { community health } \\
\text { committee members } \\
3 \text { Klls and } 4 \text { FGDs with } 34 \mathrm{CHWs} \\
\\
\text { KIlls with } 5 \text { service recipients }\end{array}$ & $29,35,39,45$ \\
\hline Nigeria: Abuja & $\begin{array}{l}\text { Community health } \\
\text { extension workers } \\
\text { Junior community health } \\
\text { extension workers }\end{array}$ & $\begin{array}{l}9 \text { KIls with } 9 \text { programme staff } \\
5 \mathrm{KIls} \text { with } 5 \text { health professionals } \\
1 \mathrm{KII} \text { and } 2 \text { FGDs with } 11 \\
\text { community health committees } \\
9 \mathrm{KIls} \text { and } 1 \mathrm{FGD} \text { with } 15 \mathrm{CHWs} \\
3 \mathrm{KIls} \text { and } 1 \mathrm{FGD} \text { with } 8 \text { service } \\
\text { recipients }\end{array}$ & $30,32,34,40,43,46$ \\
\hline
\end{tabular}

$\mathrm{CHW}$, community health worker; FGD, focus group discussion; KII, key informant interview.

embedded within the narrative to illustrate the various patterns noted in the data.

\section{Patient and public involvement statement}

There were no patients involved in this research.

\section{RESULTS}

This study compared 10 different cadres of CHWs across five countries. Irrespective of CHW training duration and characteristics, all CHWs identify pregnant women, provide health education and screen for maternal health conditions. Therapeutic care, skilled antenatal care, birth attendance and provision of long-acting reversible contraceptives are provided by Level 2 paraprofessional $\mathrm{CHWs}$ with more than 3 months of training. In contrast, community mobilisation and patient tracking are often done by Level 1 paraprofessional CHWs with less than 3 months of training. Across the study countries, CHWs were under pressure to provide MNH services beyond their scope of practice and there was a tendency for CHWs in some settings to take on a healthcare facilitybased role at the expense of a more traditional community-based role.

\section{Training duration and characteristics of the CHW providing MNH services}

Drawing on policy documents and perspectives of study participants, the 10 different CHW cadres from the study countries are categorised into either Level 1 or 2 paraprofessional CHWs based on their training duration (figure 1). All the CHWs in the study countries had a secondary level education, but there were significant differences in pre-service training duration. There is a general trend in which the longer the CHW training, the higher the likelihood of the CHW being facility based. The first category, Level 1 paraprofessional CHWs have prior secondary education and subsequent pre-service training lasting between 8 and 21 days. This category includes FWA and HA (Bangladesh), ASHA (India) and CHV (Kenya). Furthermore, Level 1 paraprofessional CHWs are often community residents selected by fellow community members in collaboration with government representatives. They are expected to provide most of their services through community-based activities such as home visits and community outreaches. ${ }^{21-25}$ Level 2 paraprofessional CHWs have post-secondary pre-service training in a 
Community-based

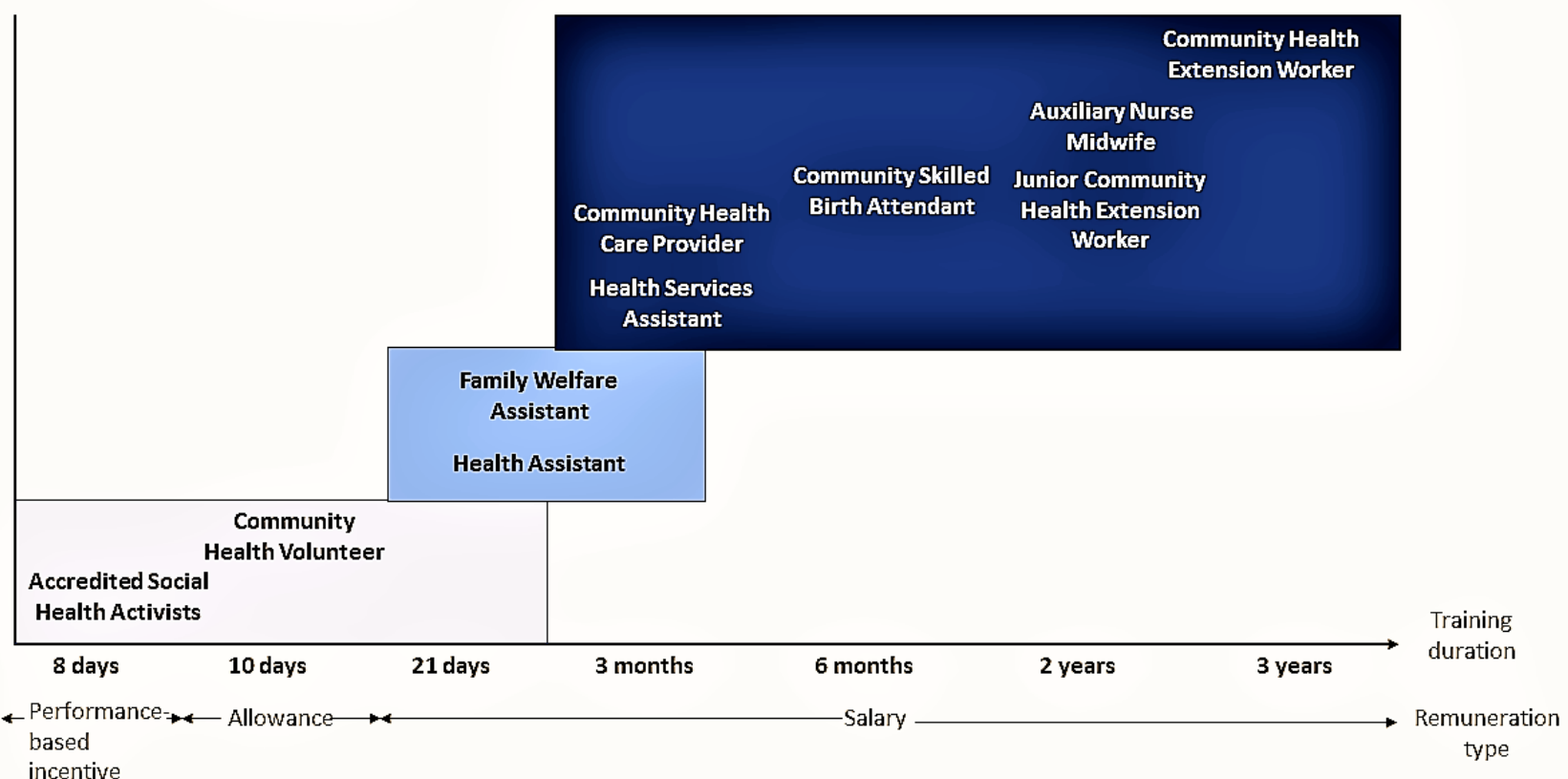

Figure 1 Type of community health worker, whether community-based or facility-based, length of training and type of remuneration across five study countries.

government-accredited institution lasting anywhere between 3 months and 3 years and they are often selected by government representatives. Level 2 paraprofessional CHWs tend to be facility based; relying on women and babies to access services at the healthcare facility where they are based. They conduct occasional home visits and community outreaches. ${ }^{232627}$ This category includes CHCP and CSBA (Bangladesh), ANM (India), HSA (Malawi), CHEW and JCHEW (Nigeria).

CHW selection criteria equally vary with training duration. In contrast to CHWs who are selected as CHWs before receiving pre-service training, CHWs with the longest training (2-3 years) are appointed only after completing their pre-service training and may not be members of the community they are asked to serve. Programme staff in Nigeria explained that CHWs with the longest training may not be from the community because there are communities which lack indigenes with the required academic grades to gain admission to the training school. Consequently, the government has "no choice but to post somebody from elsewhere".

\section{CHW scope of practice in MNH care}

While all the CHW categories have key roles in antenatal care, labour and delivery, postnatal and neonatal care, and family planning, there are significant variations in their levels of involvement and approach to service delivery. Figure 2 illustrates the variation in CHW scope of practice with the duration of pre-service training. It builds on WHO's international classification of health interventions ${ }^{19}$ to classify
CHW services as either therapeutic, diagnostic, preventive and promotive, and auxiliary. Furthermore, it situates these interventions within the MNH service package and notes that Level 2 paraprofessional CHWs have a range of roles in MNH-related diagnosis, therapeutic services, health promotion and disease prevention. In contrast, Level 1 paraprofessional CHWs have more auxiliary roles such as community mobilisation.

\section{Antenatal care}

CHWs play an important role in identifying pregnant women, helping diagnose existing and pregnancy-related conditions, promoting health, preventing disease and treating minor health conditions in pregnant women. ${ }^{2328-32}$ These roles are illustrated in the subthemes below.

\section{Identification of pregnant women and diagnosis of pregnancy- related and pre-existing health conditions}

Irrespective of training duration, CHWs are aware of and establish pregnancy through a history of two consecutive missed periods and/or if there are other early pregnancy symptoms. CHWs with longer pre-service training such as ANMs (India), CSBAs (Bangladesh), CHEWs and JCHEWs (Nigeria) are expected to make the diagnosis of pregnancy using a urine pregnancy test. ASHAs (India), with shorter pre-service training, require additional relevant in-service training to be able to conduct a pregnancy test. ${ }^{24}{ }^{33-35}$ Study participants in the African study countries generally had a different approach as the news of an early pregnancy is often held in secrecy due to 


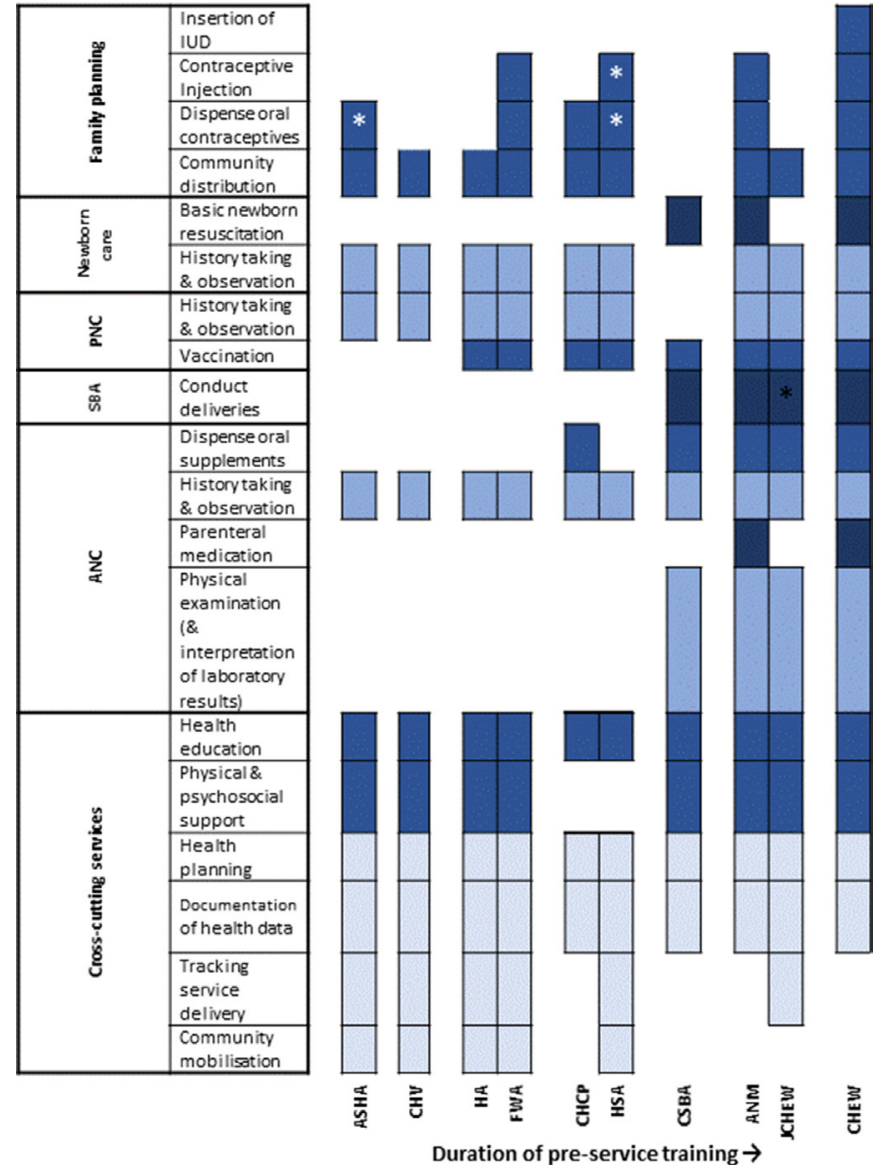

\begin{tabular}{|l|l|}
\hline & Therapeutic services \\
\hline & $\begin{array}{l}\text { Health promotion and disease } \\
\text { prevention }\end{array}$ \\
\hline & Diagnosis \\
\hline & Auxiliary services \\
\hline
\end{tabular}

*Requires additional in-service training to provide services

Figure $2 \mathrm{MNH}$ care and scope of practice by $\mathrm{CHW}$ cadre. ANC, antenatal care; ANM, auxiliary nurse midwife; ASHA, accredited social health activist; CHCP, community healthcare provider; $\mathrm{CHEW}$, community health extension worker; $\mathrm{CHV}$, community health volunteer; $\mathrm{CHW}$, community health worker; CSBA, community skilled birth attendant; FWA, family welfare assistant; HA, health assistant; HSA, health surveillance assistant; JCHEW, junior community health extension worker; $\mathrm{MNH}$, maternal and newborn health; PNC, postnatal care; SBA, skilled birth attendant.

cultural reasons and consequently CHWs generally rely on existing social networks to identify pregnant women (box 1 Quote 1).

According to policy, CHWs are expected to identify pre-existing or pregnancy-related health conditions with their level of involvement varying with duration of pre-service training. All CHWs are expected to be able to take a history to identify pre-existing or pregnancy-related diabetes mellitus or hypertension or danger signs such as vaginal bleeding or convulsion. In addition, they may monitor weight gain and blood pressure. ${ }^{23} 28-32$ However, physical and obstetric examination, interpretation of laboratory tests or ultrasound reports to differentiate between normal pregnancy and
Box 1. Quotes 1-9

Quote 1: "There is a group called Amayi Achinsinsi [in English, "secret women"], which they [HSA] use to identify pregnant women. Culturally, pregnancy is not revealed to anybody to avoid being bewitched". Nurse-midwife, Malawi

Quote 2: "When you go to family planning, they [nurse-midwives] will say you are not supposed to be there, it is for nurses. You go to antenatal [clinic], they say no, it is not community... we are trained to do all aspects of the work. If tomorrow I am posted some where, will I be able to stay and practise what I have been taught in school while I have not been practising it?" CHEW, Nigeria

Quote 3: "Suppose ANC case comes here, haemoglobin can't be done blood sugar level can't be done, everything can't be managed here. ANC cases have to go to the Rural Hospital... no sonography centres here [sub-centre]". ANM, India

Quote 4: "The doctor asked me to take her [woman in labour] to the General Hospital... The doctor called me to his room and told me to take the delivery box with me and told me to cut the umbilical cord if she delivers in the vehicle. And while travelling if anything happens to mother or baby then whose responsibility is that?" ASHA, India Quote 5: "When a woman is coming with the 'head-on-perineum', as a JCHEW and you are the one on duty, you don't have anybody to supervise you, would you refer such a woman? They eventually take the delivery with caution. So, they end up doing what they are not supposed to do". Programme staff, Nigeria

Quote 6: "... when you go there you find out she [pregnant woman in labour] needs to be transferred yet she does not have a card [facility registration card], money or anything, and the distance to the hospital is also far. If she delivers at home you have to help, maybe you don't have razor blade or thread, so we are forced to use knives because there is nothing and the baby has come out". CHV, Kenya

Quote 7: "A midwife is saying that JCHEW cannot receive delivery but in a state like Jigawa State may need 300 midwives, but Jigawa cannot produce ten midwives, can we allow women to continue dying?" Programme staff, Nigeria

Quote 8: "We don't leave the delivery for them [CHEW trained in skilled birth attendance] to handle... they only assist". Nurse-midwife, Nigeria

Quote 9: "We bring labour patients over here [primary healthcare centre] because all this area [sub-centre] comes under a hilly area. It is difficult to get phone connectivity [to get an ambulance during an emergency]. It is better to take them here and keep them under [the] observation of [a] Medical Officer". ANM, India.

high-risk pregnancies are within the exclusive remit of Level 2 paraprofessional CHWs with pre-service training of greater than 6 months. These CHWs include CSBAs (Bangladesh), ANMs (India), and CHEWs and JCHEWs (Nigeria). ${ }^{32} 34$

In practice, there are situations in which CHWs are unable to assess pregnant women for pregnancy-related and pre-existing health conditions even when this role is included in their scope of practice. CHWs working alongside nurse-midwives such as CHEWs in Nigeria played a more limited role than stipulated in their scope of practice because the nurse-midwives 'prevented' the CHWs from providing some MNH services (box 1 Quote 2). Despite these CHWs being trained to competently undertake the task. ${ }^{35}$ Other CHWs despite receiving required training ${ }^{23}$ 
are unable to provide antenatal care because of lack of equipment and consumables and consequently expressed that they were 'forced' to refer the service recipients (box 1 Quote 3).

\section{Health promotion and disease prevention}

Regardless of training duration, CHWs talk with pregnant women about a healthy lifestyle in pregnancy, distribute commodities such as mosquito nets and facilitate birth and emergency preparedness in which they advise regarding place of birth and developing a plan for unexpected adverse events or complications that may occur during pregnancy, birth or in the immediate postnatal period, for example, where and how to organise transport and/or who might donate blood..$^{2326-31}$

Vaccination and dispensing micronutrient supplements and oral medications rest primarily with Level 2 paraprofessional CHWs (CHCPs (Bangladesh), ANMs (India), HSAs (Malawi), CHEWs and JCHEWs (Nigeria)). This role includes dispensing supplements such as iron tablets, folate and calcium, and providing intermittent preventive treatment of malaria. ${ }^{31}{ }^{33-36}$ However, Level 1 paraprofessionals such as FWAs and HAs (Bangladesh) provide tetanus vaccination alongside Level 2 paraprofessional CHWs because of the level of specialisation in their training and role. ${ }^{34}$ Level 2 paraprofessional CHWs with the longest training have additional roles in disease prevention. CHEWs (Nigeria) initiate anti-retroviral therapy for HIV-positive pregnant women to prevent mother-to-child transmission of HIV. ${ }^{35}$ Similarly, ANMs (India) administer a pre-referral dose of parenteral dexamethasone for preterm birth. ${ }^{37}$

\section{Provision of therapeutic care for minor ailments}

Policy documents show that management of minor health conditions such as mild anaemia and treatment of malaria in pregnancy is done only by Level 2 paraprofessional CHWs. ${ }^{238-36}$

\section{Labour and delivery}

In line with policy, Level 1 paraprofessional CHWs tend to play key roles during the latent phase of labour while management of the active phase of labour is expected to be provided only by Level 2 paraprofessional CHWs trained as skilled birth attendants. However, study participants highlighted policy-practice gaps and challenges with implementation of this policy.

\section{Identification of women in labour and serving as birth companions}

Level 1 paraprofessional CHWs who reside in the community are often informed when pregnant women experience clinical features signalling the onset of labour. ${ }^{32} 33$ These CHWs are expected to act as birth companions, facilitating transport to the healthcare facility and providing psychosocial support. According to an ANM (facility-based) in India, residing within the community makes ASHAs (community-based) more accessible and approachable as community members view them as 'familiar faces'.

\section{Monitoring labour and conducting deliveries}

Both policy documents and participants' perspectives confirmed that only Level 2 paraprofessional CHWs who have received training in skilled birth attendance are expected to monitor the progress of labour, conduct the delivery, and identify maternal and fetal complications. These CHWs include the CSBAs (Bangladesh), ANMs (India) and CHEWs (Nigeria) while JCHEWs (Nigeria) monitor labour but require additional in-service training to be able to conduct deliveries. ${ }^{2734-3638}$

In contrast to the stated policies, participants across all study countries reported that CHWs (not trained in skilled birth attendance) do conduct deliveries while those trained in skilled birth attendance may not actually do so. Untrained CHWs complained that they were under pressure to conduct deliveries during emergencies and/or in the absence of formally trained nurse-midwives or in situations where the service recipients cannot afford the cost of healthcare facility birth (box 1 Quotes $4,5,6)$. Programme staff in Nigeria added that CHWs often provide services beyond their competencies in order to preserve their reputation within the community, especially as 'most people feel when you refer a patient you are not competent'. Significant within-country variation in the density of health professionals across Nigeria was seen as a justification for CHWs to have an expanded scope of practice in regions with a low density of health professionals (box 1 Quote 7).

In contrast, some CHWs trained in skilled birth attendance reported being unable to conduct deliveries despite being trained. Reasons given were that in areas with a relatively high density of nurse-midwives, they might wish to reserve the right to conduct deliveries to their own cadre only (box 1 Quote 8), and sometimes referrals were made because of logistic challenges (box 1 Quote 9).

\section{Postnatal care}

The role of the CHW was found to relate to the stage of the postnatal period: immediate, early and late postnatal periods. Policies show that Level 2 paraprofessional CHWs trained in skilled birth attendance provide immediate postpartum care in the healthcare facilities while all CHWs in all study settings, irrespective of training, conduct postnatal home visits including identifying danger signs, preventing disease and promoting health among postnatal mothers. ${ }^{23} 28-3234$

\section{Assessment for and prevention of postpartum haemorrhage}

As a policy, Level 2 paraprofessional CHWs (trained in skilled birth attendance) are expected to facilitate early initiation of breast feeding as a 'measure to prevent postpartum haemorrhage' and conduct clinical observation and examination to diagnose postpartum haemorrhage during the immediate postnatal period. ${ }^{2328-32} 34$ 


\section{Box 2. Quotes 10-15}

Quote 10: "If we are seven CHEW in total and two or three are going for outreach, how many will remain in the various departments of the clinic?" CHEW, Nigeria

Quote 11: "It is only when we are going for immunisation outreach that we have transportation allowance". CHEW, Nigeria

Quote 12: "Yes, when they [CHW] come, they focus on administering immunisation to children, not on the nursing mothers [explaining how CHW do not provide community-based postnatal services to women]". Service recipient, Nigeria

Quote 13: "Her [ANM] village is the hilly one; vehicles do not go there very remote place, still many delivery cases. There is a single sister, she is expected to visit the villages [to provide postnatal care], then she will be back to conduct deliveries". ASHA, India

Quote 14: "Birth control programme is their [FWA] main work". Programme staff, Bangladesh

Quote 15: "FWV [Female Welfare Visitors] give the first dose of the injection, and from the second dose [it is done by] our FWA, those at the field level... and others". Programme staff, Bangladesh

\section{Assessment of postpartum sepsis in the early and late postpartum period}

Policy documents and the different study participants report that all CHWs are expected to assess women for postpartum sepsis during home visits. ${ }^{2328-3234}$ In line with policy, an ANM in India stated that they observe "which colour of discharge they have got" which aids their clinical diagnosis of postpartum sepsis.

\section{Promotion of breast feeding}

As a policy, all CHWs, irrespective of training, are expected to support breast feeding, facilitate appropriate positioning and attachment of the newborn, prevent cracked nipples and promote breast feeding. ${ }^{23} 28-3234$

While most of the policy documents reviewed explicitly expect CHWs to provide community-based postnatal care, in practice, many of the Level 2 paraprofessional CHWs are unable to conduct postnatal home visits. Common reasons for this include inadequate number of CHWs and prioritisation of facility-based care at the expense of traditional community-based roles (box 2 Quote 10). Other reasons include lack of financial support for community visits (box 2 Quotes 11, 12), competing work demand at the healthcare facility and difficult topography (box 2 Quote 13).

\section{Newborn care}

Study participants' description of CHWs' roles in neonatal care shows that practice largely aligns with policies. Consequently, this section reflects findings from the policy documents and, where necessary, perspectives of study participants clarify policies relating to their roles in newborn care. Largely, CHWs who have received training in skilled birth attendance provide initial facility-based roles while other services are shared among CHWs irrespective of content and duration of training.

\section{Immediate care of the newborn}

As per policy, CHWs trained in skilled birth attendance are expected to clean, dry and wrap the newborn to prevent hypothermia and provide basic resuscitation of a newborn when required. ${ }^{23}$

\section{Health promotion and disease prevention}

All CHWs are expected to prevent umbilical cord infection by applying chlorhexidine gel to the umbilical stump and encouraging nursing mothers to do the same. They are also to facilitate Kangaroo-mother care for low-birthweight babies. ${ }^{23}$ 28-32 3435 However, only CHWs with greater than 3 weeks of pre-service training are involved in administering age-appropriate vaccines to newborn babies. $^{2328-32} 34-36$

\section{Identification of neonates with poor health status}

As a policy, all CHWs are expected to identify the sick newborn through clinical history and inspection. This includes anthropometric measurements of the infants to track growth, counting respiratory rate and checking body temperature. ${ }^{3134}$

\section{Family planning}

Policies and perspectives of the study participants illustrate how family planning roles of CHWs vary with CHW pre-service training duration or specialisation. While all CHWs (irrespective of training duration) provide shortacting contraceptives, long-acting contraceptives are exclusively provided at the healthcare facility by CHWs with longer training.

\section{Providing short-acting contraceptives}

The role of CHWs in providing short-acting contraceptive depends on the duration of pre-service training of CHWs and receipt of specialisation training. According to policy documents, all CHWs, irrespective of training, provide contraception-related health education and are expected to distribute condoms. Level 2 paraprofessional CHWs provide oral contraceptive pills at the healthcare facility except for CHCPs, CSBAs (Bangladesh) and JCHEWs (Nigeria). The non-involvement of these Level 2 paraprofessional CHWs in providing oral contraceptive pills may be explained in part by the availability of another CHW cadre providing oral contraceptive pills in the healthcare facility such as CHEWs in Nigeria. However, Level 1 paraprofessionals who have received some form of specialisation training provide oral contraceptive pills in the community and, where necessary, in the healthcare facility. For example, FWAs (Bangladesh) provide oral contraceptive pills at both the healthcare facility and in the community after focused pre-service training. ASHAs (India) and CHVs (Kenya) are equally allowed to distribute oral contraceptive pills in the community after a family planning-related in-service training. ${ }^{2328-32} 34$

Similarly, policy documents show that contraceptive injections are provided only by Level 2 paraprofessional CHWs such as ANMs (India), HSAs (Malawi), CHEWs and JCHEWs (Nigeria). ${ }^{358-40}$ Exceptions include CHCPs and 
CSBAs in Bangladesh who are Level 2 paraprofessionals but do not provide contraceptive injections. This may be explained by the availability of FWAs (Bangladesh) who despite being Level 1 paraprofessional CHWs administer contraceptive injection because of their family planningfocused role and specialisation training ${ }^{34}$ (box 2 Quote 14). As explained by programme staff in Bangladesh, FWAs are only permitted to administer follow-up doses of contraceptive injection after the service recipient has been reviewed and had the first dose administered by a female welfare visitor (a relatively senior family planning health worker) (box 2 Quote 15).

\section{Providing long-acting reversible contraception}

Both policy documents and perspectives of study participants show there is a consensus regarding the role of CHWs in providing long-acting reversible contraceptives. While insertion of intrauterine contraceptive devices and implants are within the exclusive remit of CHWs with up to 2 years of pre-service training (ANMs and CHEWs), only CHEWs (3-year pre-service training) are expected to insert implant contraceptives. ${ }^{23} 39$

\section{Cross-cutting MNH roles of CHWs}

CHWs engage in a variety of cross-cutting roles which are often considered 'auxiliary services' and are needed to support health service delivery and inform decision-making.

\section{Collection of health data and health planning}

According to policy documents, all CHWs are involved in the collection of health data including identifying and documenting the cause of deaths in the community. These data tend to inform the community, facility and subnational level health plans. ${ }^{2433} 3441$ Study participants in Bangladesh, Kenya and Malawi mentioned that CHWs are often the 'first people to know' about deaths in the community following which they 'discuss the cause of death' with members of the deceased's household. They document relevant information relating to the medical cause and social factors that contributed to maternal or newborn deaths. This information subsequently informs the content of health education sessions in the prevention of maternal and newborn deaths. Additionally, health professionals conduct further review of CHW findings and send a report to the district to inform subnational health plans.

According to programme staff in Bangladesh, India and Malawi, CHW data are aggregated at subnational level to inform programme planning. A Programme staff in Malawi described how the review of 'data from the catchment area such as maternal and neonatal deaths' often informs prioritising the in-service training of HSA delivering services 'in hard-to-reach regions'.

\section{Patient tracking and community mobilisation}

Policy documents and study participants' perspectives show that conducting home visits to track receipt of $\mathrm{MNH}$ care and community mobilisation are key roles of
Level 1 paraprofessional CHWs. These CHWs include FWAs and HAs (Bangladesh), ASHAs (India) and CHVs (Kenya) who are based in the community. Programme staff in Kenya explained how CHVs play ' $a$ very key role in tracing defaulters'with the aim of 'connecting defaulters'back to facility-based services.

In comparison with other study countries, there are no community-based Level 1 paraprofessional CHWs in Malawi and Nigeria. As such, Level 2 paraprofessional CHWs in these countries largely rely on community-based volunteer groups and members of the community health committee to mobilise pregnant women and nursing mothers towards facility-based care. ${ }^{28} 3138$ A member of the community health committee in Nigeria explained that the "WDC [Ward Development Committee] are people living within the community, people they know; we [WDC] can interact with them, get their husbands from our meetings, from our churches, from our local mosques... and that is how we are able to mobilise them to be coming to the clinic".

\section{DISCUSSION}

CHWs in our study countries attained secondary education but differ based on training duration and primary workstation (facility or community). Subsequently, our findings highlight how the characteristics and roles of these CHWs in MNH care vary with training duration and workstation. Additionally, it underscores contextual challenges to implementing policies relating to $\mathrm{CHW}$ roles in MNH care.

\section{Training duration and characteristics of $\mathrm{CHWs}$}

Level 1 paraprofessional CHWs in the study countries have shorter pre-service training (8-21 days) and tend to be community-based and then provide most of their services through home visits. Hence, Level 1 paraprofessional CHWs tend to have characteristics that align more with international definitions of CHW which emphasise community membership. ${ }^{42-44}$ In contrast, Level 2 paraprofessional CHWs have longer training (3 months-3 years) and tend to be facility-based and may provide most of their services within government-owned healthcare facilities. These CHWs may not be from the community they serve. While international definitions emphasise community membership to ensure social acceptance by community members, these definitions fail to recognise the difficulty in identifying qualified $\mathrm{CHW}$ candidates to serve as facility-based Level 2 paraprofessional CHWs in some hard-to-reach communities with low literacy rates. ${ }^{456}$ Policy-makers and programme planners involved in selecting Level 2 paraprofessional CHWs in hard-to-reach areas (with low literacy rates) may need to review and revise educational requirements for selecting this category of CHWs as these areas may have culturally competent candidates who do not meet national CHW educational requirements. This would promote selection of CHWs who are from the community they serve and reflect the sociodemographic characteristics of service 
recipients. Policy-makers may draw from a Nigerian policy document which illustrates attempts to design flexible school admission requirements in order to have more candidates qualifying from educationally disadvantaged areas which may not readily have eligible candidates based on present admission requirements. ${ }^{47}$

\section{Training duration and CHW scope of practice in MNH}

The roles of CHWs in MNH care tend to vary according to CHW category and the cultural context where CHWs provide these services. Irrespective of training duration, all CHWs in the study countries identify pregnant women, provide MNH-related health education and screen for diseases and health conditions that require referral of mothers and newborns.

Therapeutic care, skilled antenatal care and birth attendance are within the exclusive remit of Level 2 paraprofessional CHWs who have received longer training and often facility-based under the direct supervision of nurse-midwives or have referral links to Comprehensive Emergency Obstetrics and Neonatal Care centres. In contrast, auxiliary roles such as community mobilisation and patient tracking are often done by Level 1 paraprofessional CHWs or volunteer groups who reside in the same community as their service recipients.

As global and local policy-makers in community health continue to deliberate on harmonising CHW services with those of health professionals and defining the roles of CHWs in relation to other health workers, ${ }^{48}{ }^{49}$ our findings provide a useful guide for the discussions. Similar to our study findings, qualitative studies exploring the roles of doctors and different categories of nurses in primary healthcare settings highlight the influence of educational level and duration of pre-service training in informing their roles in service delivery. ${ }^{50} 51$ Policy-makers involved in developing CHW scope of practice may consider segmenting the MNH service package and subsequently assigning MNH tasks to reflect the duration and content of training, and primary workstation of each CHW category.

However, local policy-makers should consider contextual factors in defining the approach to service delivery and identifying other stakeholders required to complement CHW services, especially as our study underscores the need for community groups in identifying pregnant women in Africa due to the secrecy surrounding pregnancy. This is in line with a qualitative study exploring indigenous practices of pregnant women in South Africa which underscores the cultural sensitivity of pregnancy-related issues and shows that women delay reporting their pregnancies and commencing antenatal care attendance because of the superstitious belief that jealous community members with supernatural powers may cause them to have abortions. ${ }^{52}$ Subnational policy-makers in Africa should consider mapping out the various community groups that community women confide in and share the news of their pregnancies. Subsequently, they may strengthen the communication link between these community groups and CHWs who would link them with skilled antenatal care without breaching confidentiality and privacy.

\section{Policy-practice gaps relating to $\mathrm{CHW}$ scope of practice in MNH}

This study notes policy-practice gaps in relation to $\mathrm{MNH}$ roles of CHWs. First, our findings illustrate an informal expansion of CHW roles in MNH care, often beyond their competencies particularly during emergencies where health professionals are unavailable, and referral may not be feasible. Findings of a systematic review of CHW programmes in countries from all income status illustrate this challenge. It shows that CHWs in low-income to middle-income countries (LMICs) are more likely to be confronted with health issues beyond their scope of practice due to a shortage of health professionals as compared with their counterparts in high-income countries. ${ }^{7}$ This challenge is often exacerbated by maldistribution of the scarce health workforce in the various LMICs. ${ }^{46}$ Policy-makers in areas with the dual challenge of low density of health professionals and pressing local health needs may draw from a qualitative study exploring task-shifting of clinical roles from nurses to HSAs to meet local health needs in Malawi. ${ }^{53}$ The study highlights an opportunity for policy-makers to decide on the feasibility of increasing the depth of CHW scope of practice towards specialisation in a few technical roles or expanding the breadth with non-specialisation in many less-technical roles. ${ }^{53}$ This key decision may inform training a few CHW towards specialisation to meet local health needs of high priority. Moreover, our multiple-case study illustrates how FWAs (Bangladesh) undergo a 3-week specialisation training to meet the local need for family planning services. For researchers, there is a range of research themes to be explored. These themes relate to evaluating and comparing the effectiveness of expanding their scope of practice towards specialisation in a few technical roles as opposed to non-specialisation in many less-technical roles.

Second, some CHWs have a limited role in MNH due to monopolistic control of certain roles by health professionals and logistic challenges with telecommunication and transportation. To minimise this challenge, there is a need to develop and implement policies that clearly stipulate the roles of each cadre of health worker in a multidisciplinary primary healthcare team. ${ }^{54}$ This approach may be key to ensuring effective and productive tasksharing between CHWs and health professionals. Policy-makers working in regions with communication and transportation challenges that cause CHWs to engage in precautionary referral of women in labour may consider limiting the roles of CHW in these regions to antenatal care only. Subsequently, pregnant women may be referred to waiting rooms of referral centre at 36 weeks' gestation as is the case in some LMICs. ${ }^{55-57}$

Lastly, some Level 2 paraprofessional CHWs in the study countries have roles skewed towards facility-based 
services at the expense of their community-based services. This study shows that as CHWs take up additional facility-based roles, they inadvertently neglect some of their traditional community-based roles such as postnatal home visits. This challenge is often exacerbated by limited or lack of financial support for transport to the community. Our findings corroborate those of a qualitative study exploring task-shifting of clinical roles from nurses to HSAs in Malawi which noted that HSAs tend to neglect their community-based roles in order to fulfil the new work demands in the healthcare facility. ${ }^{53}$ Responsible task-shifting would entail identifying and training another CHW cadre to provide services (especially community-based services) previously provided by CHWs who now have additional roles in the healthcare facility due to task shifting. This is important to prevent widening the equity gap in service coverage of hard-toreach communities where some community members may lack physical and financial access to facility-based services. More so, evidence suggests that community-based services provide better financial and physical access to MNH services in hard-to-reach populations than facility-based services. ${ }^{58}{ }^{59}$ Hence, global and local policy-makers must review the unintended effect of taskshifting facility-based roles to CHWs (at the expense of their traditional community-based roles) and its broader implication on universal health coverage.

\section{Study strengths and limitations}

To our knowledge, this is the first qualitative study exploring the scope of practice of 10 different CHW cadres providing MNH services in five LMICs across two continents. Furthermore, it uses a working definition to purposively select CHWs and competency-based categories to objectively compare CHWs across continents. However, despite reviewing the policy documents of study countries and holding discussions with in-country partners while developing the study proposal, it was difficult to map out all the key groups of CHWs providing $\mathrm{MNH}$ services in these countries. Due to time and budget constraints, the primary research team had limited in-country discussions with the staff of governmental and non-governmental organisations without engaging community-level stakeholders. Consequently, the team left out some community support groups who would have qualified as lay health workers (working with paraprofessional CHWs) based on the working definition of CHWs.

\section{CONCLUSION}

CHWs are geographically and socially well positioned to provide MNH services to communities especially if they live in and/or are from the community. Globally, policy-makers continue to 'reposition' the role of CHWs including regarding the provision of $\mathrm{MNH}$ services. There is a need to categorise CHWs based on the level of education and duration of pre-service training as this largely informs their roles with regard to provision (or not) of aspects of MNH services. Policy-makers must, however, recognise the tensions between CHW policy and practice in which CHWs may have an expanded, limited or skewed role in MNH care due to local realities which shape their practice. Subsequently, they will be better positioned in revising existing CHW scope of practice to respond to local health needs and priorities. Twitter @CMNHLSTM

Acknowledgements The authors acknowledge the data collection support provided by LSTM Kenya, Malawi and Nigeria; Centre for Injury Prevention and Research Bangladesh; and Foundation for Research in Community Health India. The authors would like to thank Dr Helen Smith for reviewing the PhD thesis that informed this manuscript and Caroline Hercod for editing the final manuscript.

Contributors $\mathrm{A} 0$ and $\mathrm{NvdB}$ conceived the study with contributions from BM and SB-Z. AO collected and analysed the data and drafted the PhD thesis which informed the manuscript. NvdB, BM and SB-Z reviewed the thesis and contributed to interpretation of the results. $A O$ drafted the initial version of the manuscript while $\mathrm{NvdB}, \mathrm{BM}$ and SB-Z reviewed it. NvdB, BM and AO drafted the final version of the manuscript.

Funding This study is funded by Department for International Development (DFID) through the Liverpool School of Tropical Medicine "Making it Happen" programme (202945-101).

Disclaimer The funders played no role in drafting the manuscript or the choice of journal where the manuscript is to be submitted.

Competing interests None declared.

\section{Patient consent for publication Obtained.}

Ethics approval The Liverpool School of Tropical Medicine, Liverpool, UK granted full ethical approval (LSTM 15.007). Ethical approval was also obtained from each of the study country-specific research ethics committee: Ethical Review Committee, Centre for Injury Prevention and Research, Bangladesh; Institutional Research Ethics Committee (IREC) of The Foundation for Research in Community Health (IREC/2015/11/4/2) Kenyatta National Hospital and University of Nairobi, Ethics and Research Committee, Nairobi, Kenya (P485/07/2015); The College of Medicine Research and Ethics Committee, College of Medicine, Blantyre, Malawi (P.07/15/1765); Federal Capital Territory Health Research Ethics Committee, Abuja (FHREC/2015/01/52/24-08-15).

Provenance and peer review Not commissioned; externally peer reviewed.

Data availability statement Data are available on reasonable request.

Open access This is an open access article distributed in accordance with the Creative Commons Attribution Non Commercial (CC BY-NC 4.0) license, which permits others to distribute, remix, adapt, build upon this work non-commercially, and license their derivative works on different terms, provided the original work is properly cited, appropriate credit is given, any changes made indicated, and the use is non-commercial. See: http://creativecommons.org/licenses/by-nc/4.0/.

\section{REFERENCES}

1. WHO. Working together for health: the world health report 2006. Geneva WHO; 2006. http://www.who.int/whr/2006/whr06_en.pdf? ua $=1$

2. WHO. Who guidelines on health policy and system support to optimize community health worker programmes. Geneva WHO; 2016. http://www.who.int/hrh/community/CHW_gdlns_IPP_ 2Dec2016_c_web.pdf?ua=1

3. UN. The Millennium Development Goals report 2014. New York: United Nations; 2014. http://www.un.org/millenniumgoals/2014 MDG report/MDG 2014 English web.pdf

4. Scheffler RM, Herbst $\mathrm{CH}$, Lemiere $\mathrm{C}$, Campbell J. Health labor market analyses in low- and middle-income countries: an evidencebased approach. directions in development. Washington, DC World Bank; 2016. https://openknowledge.worldbank.org/handle/10986/ 25137

5. WHO. Global health workforce shortage to reach 12.9 million in coming decades, 2013.

6. Global Health Workforce Alliance. Synthesis Paper of the Thematic Working Groups - Health Work Force 2030-towards a global strategy on human resources for health. Geneva: WHO, 2015. 
7. Glenton C, Colvin C. Barriers and facilitators to the implementation of lay health worker programmes to improve access to maternal and child health: qualitative evidence synthesis. Cochrane Database Syst Rev 2013;10.

8. WHO. Monitoring the building blocks of health systems: a handbook of indicators and their measurement strategies. Geneva: WHO, 2010.

9. WHO. Classifying health workers: mapping occupations to the international standard classification. Geneva, WHO, 2010.

10. International Labour Organization. International standard classification of occupations: structure, group definitions and correspondence tables. Geneva: International Labour Organization, 2012.

11. Olaniran $A$, Smith $H$, Unkels $R$, et al. Who is a community health worker? - a systematic review of definitions. Glob Health Action 20 17;10:1272223.10.1080/16549716.2017.1272223

12. UNFPA, UNICEF, UN Women, WHO, World Bank. Strengthening the capacity of community health workers to deliver care for sexual, reproductive, maternal, newborn, child and adolescent health. Geneva: World Bank, 2015.

13. WHO. Recommendations on antenatal care for a positive pregnancy experience. Geneva, 2016.

14. Stewart A, Statistics B. Epidemiology: a practical guide. Boca Raton, Florida: CRC Press, Taylor and Francis Group, 2016.

15. Huda FA, Ahmed A, Ford ER, et al. Strengthening health systems capacity to monitor and evaluate programmes targeted at reducing abortion-related maternal mortality in Jessore district, Bangladesh. BMC Health Serv Res 2015;15:426.

16. GHWA, WHO. A universal truth: no health without a workforce. Geneva: WHO, 2014. Available: http://www.who.int/ workforcealliance/knowledge/resources/GHWA-a_universal_truth_ report.pdf?ua $=1$

17. Parternship for Maternal, Newborn and Child Health. Countdown to 2015 report: 'Unfinished business' on maternal, child health. Johannesburg, South Africa World Health Organization; 2014. http:// www.who.int/pmnch/about/governance/partnersforum/countdown/ en/index1.html

18. WHO. Accountability for women's and children's health 2014: progress report; 2014. http://www.who.int/woman_child_ accountability/about/COIA_report_2014.pdf?ua=1

19. WHO. International classification of health interventions. Geneva: WHO, 2017.

20. Boyatzis RE. Transforming qualitative information: thematic analysis and code development. Thousand Oaks, CA: Sage, 1998

21. Directorate of General Health Services. Community HMIS e-Newsletter, 2014. Available: www.dghs.gov.bd

22. Government of Bangladesh, Community Clinic Project. Revitalization of community health care initiatives in Bangladesh (RCHCIB. Dhaka: Government of Bangladesh, 2015.

23. Indian Nursing Council. Amendments for auxiliary nurses and midwives syllabus and regulation. Dehli: Indian Nursing Council, 2013.

24. Ministry of Health and Family Welfare. Annual report 2014-15. Delhi: Ministry of Health and Family Welfare; 2017. https://mohfw.gov.in/ sites/default/files/563221459875632.pdf

25. Government of Kenya. A national framework and plan of action for implementation of integrated community case management (iCCM) in Kenya, 2013-2018. Nairobi: Government of Kenya, 2013.

26. Institute for International Programmes, Johns Hopkins University. Ministry of Health Malawi, WHO, UNICEF. Quality of care provided to sick children by health surveillance assistants in Malawi. Lilongwe: Government of Malawi, 2012.

27. Community Health Practitioners Registration Board Nigeria. Curriculum of community health practitioners. Abuja: Community Health Practitioners Registration Board Nigeria, 2006.

28. National Primary Health Care Development Agency. Minimum standards for primary health care in Nigeria. Abuja: National Primary Health Care Development Agency, 2013.

29. Ministry of Health and Family Welfare. Guidelines for community process: ASHA and VHSNC. Dehli: Ministry of Health and Family Welfare, 2013.

30. National Primary Health Care Development Agency. Handbook on essential maternal and newborn care for primary health care providers. Abuja: National Primary Health Care Development Agency, 2011.

31. Ministry of Health. Health Surveillance Assistant Facilitator's Guide. Blantyre: Malawi Ministry of Health, 2009.

32. Ministry of Health. Community health volunteers (CHV): BasicModules manual. Nairobi: Ministry of Health, 2013.

33. National Rural Health Mission. National rural health mission: a promise of better healthcare for the poor. Dhaka: Ministry of Health and Family Welfare, 2006.

34. Ministry of Health and Family Welfare. Bangladesh essential health service package. Dhaka: Ministry of Health and Family Welfare, 2016.
35. Federal Ministry of Health. Task-shifting and task-sharing policy for essential health care services in Nigeria. Abuja: Federal Ministry of Health, 2014

36. National Rural Health Mission. Monitoring manual: community based monitoring of health services under national rural health mission. Dhaka: Ministry of Health and Family Welfare, 2009.

37. Ministry of Health and Family Welfare. Annual report 2014-15: child health programme. Delhi: Ministry of Health and Family Welfare, 2015.

38. Ministry of Health. In: Community-Based maternal and neonatal care: manual for health surveillance assistants. Blantyre: Malawi Ministry of Health, 2008.

39. Federal Ministry of Health. Manual for training of community health extension workers (CHEWs) on long-acting reversible contraceptive (LARC) methods (IUDs and contraceptive Implants). Trainers' manual. Abuja: Federal Ministry of Health, 2015.

40. Ministy of Health and Family Welfare. Reference manual for injectable contraceptive (DMPA). Delhi: Ministry of Health and Family Welfare, 2016.

41. WHO. National Primary Health Care Development Agency. In: Minimum standards for primary health care in Nigeria. Abuja: National Primary Health Care Development Agency, 2013.

42. WHO. Strengthening the performance of community health workers in primary health care. Geneva: WHO, 1989. Available: http://apps. who.int/iris/bitstream/10665/39568/1/WHO_TRS_780.pdf?ua=1

43. Lehmann U, Sanders D, WHO. Community health workers: what do we know about them? The state of the evidence on programmes, activities, costs and impact on health outcomes of using community health workers, Geneva, 2007. Available: http://www.who.int/hrh/ documents/community health workers.pdf

44. Health Resources and Services Administration. Community health workers national workforce study. Washington DC: Health Resources and Services Administration, 2007.

45. UNESCO. Education for all global monitoring report 2015. Regional overview: East Asia and the Pacific. New York: UNESCO, 2018. Available: http://en.unesco.org/gem-report/sites/gem-report/files/ regional_overview_EAP_en.pdf

46. WHO. Monitoring the geographical distribution of the health workforce in rural and underserved areas. Available: https://www. who.int/workforcealliance/knowledge/resources/monitoring geodistribution/en/

47. Federal Ministry of Health. National strategic health development plan (NSHDP) 2010-2015. Abuja: Federal Ministry of Health, 2010.

48. Tulenko K, Møgedal S, Afzal MM, et al. Community health workers for universal health-care coverage: from fragmentation to synergy. Bull World Health Organ 2013;91:847-52.

49. Cometto G, Ford N, Pfaffman-Zambruni J, et al. Health policy and system support to optimise community health worker programmes: an abridged WHO guideline. Lancet Glob Health 2018;6:e1397-404.

50. Desborough J, Parker R, Forrest L. Nurse satisfaction with working in a nurse led primary care walk-in centre: an Australian experience. Aust J Adv Nurs 2013;31:11-19.

51. Ladhani Z, Stevens FJ, Scherpbier AJ. Does community health care require different competencies from physicians and nurses? BMC Med Educ 2014;14:1.

52. Mogawane MA, Mothiba TM, Malema RN. Indigenous practices of pregnant women at Dilokong hospital in Limpopo Province, South Africa. Curationis 2015;38:1-8.10.4102/curationis.v38i2.1553

53. Smith S, Deveridge A, Berman J, et al. Task-shifting and prioritization: a situational analysis examining the role and experiences of community health workers in Malawi. Hum Resour Health 2014;12:24.

54. Akeju DO, Vidler M, Sotunsa JO, et al. Human resource constraints and the prospect of task-sharing among community health workers for the detection of early signs of pre-eclampsia in Ogun State, Nigeria. Reprod Health 2016;13(Suppl 2):111.

55. García Prado A, Cortez R. Maternity waiting homes and institutional birth in Nicaragua: policy options and strategic implications. Int $J$ Health Plann Manage 2012;27:150-66.

56. McIntosh N, Gruits P, Oppel E, et al. Built spaces and features associated with user satisfaction in maternity waiting homes in Malawi. Midwifery 2018;62:96-103.

57. Lori JR, Wadsworth AC, Munro ML, et al. Promoting access: the use of maternity waiting homes to achieve safe motherhood. Midwifery 2013;29:1095-102.

58. Anwar I, Sami M, Akhtar N, et al. Inequity in maternal healthcare services: evidence from home-based skilled-birth-attendant programmes in Bangladesh. Bull World Health Organ 2008;86:252-9.

59. Schleiff M, Kumapley R, Freeman PA, et al. Comprehensive review of the evidence regarding the effectiveness of community-based primary health care in improving maternal, neonatal and child health: 5 . Equity effects for neonates and children. J Glob Health 2017;7:010905. 